\title{
Challenges and opportunities in corrosion of steel in concrete
}

\author{
Ueli M. Angst
}

Received: 29 June 2017 / Accepted: 29 December 2017/Published online: 4 January 2018

(C) RILEM 2018

\begin{abstract}
This paper summarizes the grand societal, economic, technological, and educational challenges related to corrosion of steel in concrete, and presents the state-of-the-art of the most relevant issues in the field. The enormous financial impact of infrastructure corrosion seems to be inadequately balanced by educational and research activities. This presents a unique opportunity in many countries for maintaining or improving their competitiveness, given the major technological challenges can be solved. The main technological challenges are (1) the ever-increasing need to cost-effectively maintain existing, ageing reinforced concrete structures, and (2) designing durable, thus sustainable new structures. The first challenge arises mainly in industrialized countries, where there is a need to abandon conservative, experience-based decision taking and instead move to innovative, knowledge-based strategies. The second challenge regards mainly emerging countries expanding their infrastructures and where thus a major beneficial environmental impact can still be made by providing long-lasting solutions. This means to be able to reliably predict the longterm corrosion performance of reinforced concrete structures in their actual environments, particularly for modern materials and in the absence of long-
\end{abstract}

U. M. Angst ( $\square)$

Institute for Building Materials, ETH Zurich, Zurich,

Switzerland

e-mail: uangst@ethz.ch term experience. During the second half of the last century, civil engineers, materials scientists, and chemists have in many countries made considerable attempts towards understanding corrosion of steel in concrete, but many of the approaches got bogged down in empiricism. From reviewing the state-ofthe-art one can conclude that transport modeling in concrete is relatively well-advanced, at least in comparison with understanding corrosion initiation and corrosion propagation, where many questions are still open. This presents a number of opportunities in scientific research and technological development that are discussed in this paper.

Keywords Corrosion - Reinforced concrete · Infrastructure $\cdot$ Durability $\cdot$ Sustainability

\section{Introduction}

In comparison with other areas of research related to construction technology and building materials-such as digital fabrication or environmentally friendly cementitious binder systems - the science and engineering of corrosion of steel in concrete has a history of more than half a century. The advantage of this is that comparatively well documented long-time experience is available for corrosion and the related processes, mainly transport processes through the concrete cover-at least for traditional building 
materials. Regarding the durability of reinforced concrete, the processes under study are slow, i.e. they typically need time frames of years or decades to manifest. Thus, in this field, long-time documentation is highly valuable.

The downside of the topic having been tackled for several decades, however, is that concepts became deeply rooted in the research community and are generally taken for granted in daily research endeavors. It is common to study certain aspects inherent to the established concepts rather than to fundamentally question their benefit for science and engineering. One of the most prominent examples in this regard, which will also be discussed in more detail in this review, is the concept of the critical chloride content or chloride threshold value for corrosion initiation. Although it is widely known that the predictive power of this conceptual approach used to forecast the time to corrosion initiation in chloride-bearing environments is poor, the author of this article knows of no serious attempts to quit the established concept or replace it with another one.

This paper highlights a number of challenges related to corrosion of steel in concrete. Section 2 discusses societal, economic, technological, as well as educational challenges, and Sect. 3 summarizes the state-of-the-art, highlighting the areas where scientific questions still remain open. Finally, these challenges also present great opportunities in research and education for the coming generations of researchers working in the field of steel corrosion in concrete; these are discussed in Sect. 4.

\section{Challenges}

\subsection{Societal and economic challenges}

A wide variety of civil infrastructure is built in reinforced concrete (RC): bridges, tunnels, marine structures, sewer systems, dams, etc. In fact, concrete is the world's most used man-made material [1, 2]. Many of the built engineering structures are of crucial importance for a smooth and reliable functioning of economy and personal live. Infrastructure is a key factor in the competitiveness of economies; neglecting infrastructure maintenance or infrastructure expansion were recently highlighted to be among the main reasons limiting economic growth and global competitiveness in the case of the United States of America (U.S.) or India, respectively [3].

While there are many examples of excellent durability of reinforced concrete, even under harsh exposure conditions, a number of deterioration mechanisms may limit the service life of RC structures. The by far most common cause of degradation and thus poor durability of RC is corrosion of the reinforcement steel. This was apparent from different reviews, analyzing practical cases of premature deterioration of RC structures, where it was concluded that in $70-90 \%$ of the evaluated cases corrosion was the dominant degradation mechanism $[4,5]$.

Premature degradation not only concerns the safety and quality (traffic jams, infrastructure availability, etc.) of human life, the required repair work also negatively affects the environment due to the increased consumption of energy and materials. Additionally, corrosion of infrastructures causes high costs to the society [6-9]. In 2002, a comprehensive survey of the economic impact of metallic corrosion in the U.S. was published [6]. It was concluded that the overall direct costs arising from corrosion is $3.1 \%$ of the gross domestic product (GDP). With 2016s GDP, this figure becomes $\$ 575 \times 10^{9}$-annually. Note that the numbers given are only estimates of the direct costs, while indirect costs such as lost productivity, traffic jams, or negative impact on the environment, are not included. As shown in Fig. 1, approximately half of the direct costs estimated in [6] were attributed to corrosion of infrastructures such as highway bridges, gas and oil pipelines, drinking water distribution, sewer systems, and electrical utilities, while the other half is mainly due to corrosion of airplanes, ships, motor vehicles, and industrial manufacturing facilities.

Figure 1 also shows a comparison of the corrosion costs to other issues with large economic impacts such as the annual healthcare spending attributable to cigarette smoking [10] and obesity [11], or the direct costs arising from weather and climate disasters [12]. While these health- and climate-related issues are well recognized as major societal challenges and frequently appear in the media and in political debates in many regions in the world, the tremendous financial burden caused by corrosion receives comparatively little attention, particularly in Europe.

Additionally, the continuous aging of our infrastructures will aggravate this situation in the years to 


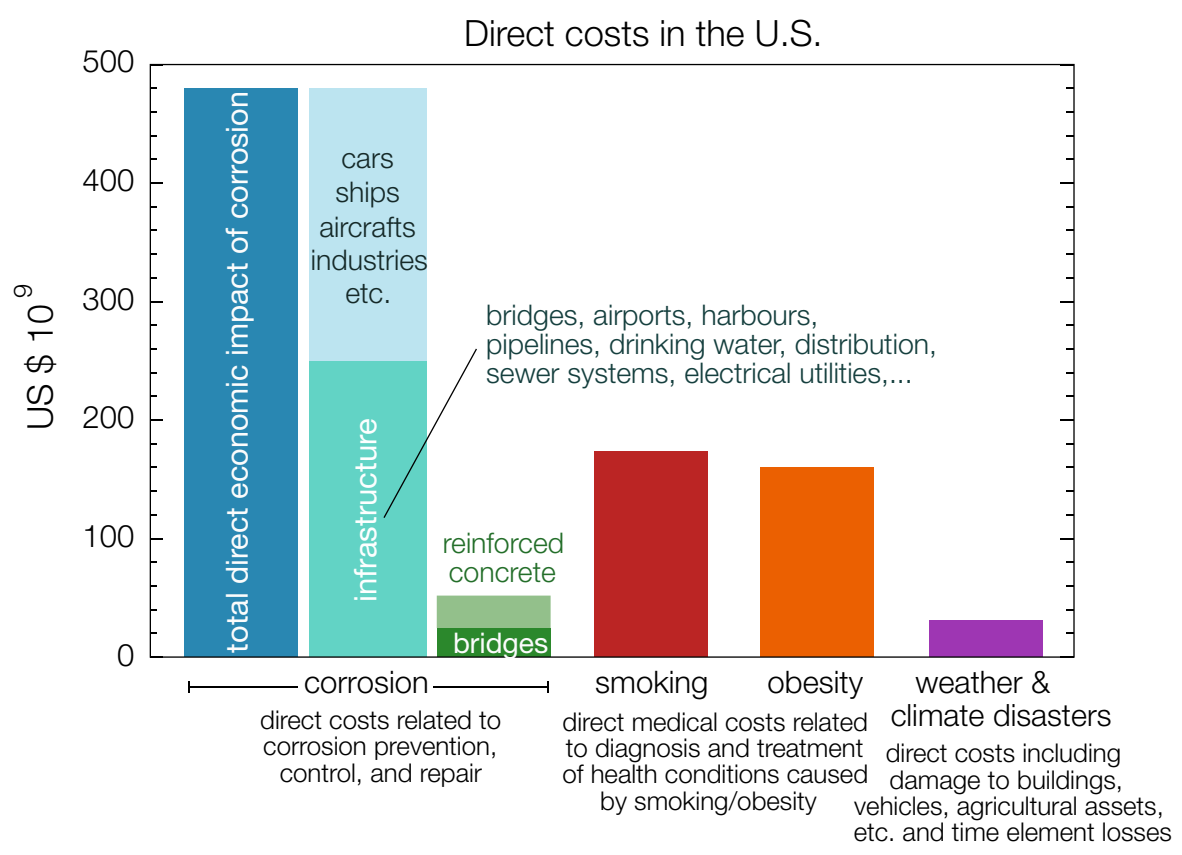

Fig. 1 Economic impact of corrosion [6] and other selected major issues in the U.S. Regarding corrosion costs attributable to concrete structures, the dark green area represents the costs for concrete highway bridges and the light green area indicates an extrapolation to other types of concrete structures not covered in [6] (parking garages, retaining walls, tunnels, etc.). The numbers for health issues include direct medical costs

come. In industrialized countries, the age profile of reinforced concrete infrastructures typically reflects a peak in construction activities around 1960-1980. Thus, most of the bridges have an age of 40 or more years and they were designed for a service life of 50 years [13]. Consequently, in the coming decades, the number of bridges that have to be operated beyond their design life will steeply increase. Based on construction dates of Dutch highway bridges and experience about time to corrosion induced damage as well as average repair lives, Polder et al. [14] estimated that the bridges needing repair will in the Netherlands increase over the coming 20 years by a factor of $2-4$, and over the coming 40 years even by a factor of 3-6. Thus, the age profile of infrastructures in industrialized countries is expected to lead to an additional increase in corrosion costs over the coming decades. related to diagnosis and treatment of health conditions caused by cigarette smoking [10] and obesity [11]. The data for weather and climate disasters [12] include physical damage to residential, commercial, and public buildings and infrastructures, vehicles, agricultural assets, and time element losses (e.g. hotel-costs for loss of living quarters). All data is representative for the years 2010-2011

\subsection{Technological challenges}

A committee recently established by the National Research Council of the U.S., given the task to identify challenges in corrosion research and engineering, concluded that the high societal costs of corrosion (Fig. 1) directly reflect the severe lack of fundamental understanding of corrosion-related degradation of materials exposed to the environment [15]. Reasons for this include the multidisciplinarity, the multi-scale nature, the absence of pure and well-defined materials, the wide variability of exposure situations, the long time spans, and the huge gap between laboratory and real conditions. The lack of fundamental understanding is also highlighted by the facts that policies to deal with corroding RC structures differ markedly from one country to another (despite the technical similarity of the problem) [16], and that engineering strategies continue relying on past experience and are largely empirical [14-16]. The presentations and the panel discussion with recognized experts at the international RILEM workshop on present and future durability 
challenges for reinforced concrete structures, held in Zurich, Switzerland, in 2012 [16], concluded that there is a strong need for a knowledge-based approach to the issue of predicting the durability of RC.

Being able to forecast the long-term durability performance of RC structures in their actual environments is on the one hand crucial for maintenance planning of existing structures, and on the other hand for designing durable and sustainable new structures (Fig. 2). Although these two challenges arise in all countries, the focus is clearly different among different regions in the world. Industrialized countries typically mainly face the problem of dealing with existing, ageing infrastructures that were built mostly in the second half of the last century, while expanding the current infrastructure constitutes a minor portion in these nations' construction activity. The current lack of knowledge (Sect. 3) forces engineers to take conservative decisions, i.e. to repair or replace structures relatively early. Considering the expected increase in needed repair works over the coming decades [14], there is certainly an urgent need to quit the current relatively conservative and thus costly approach. This can only be achieved by providing innovative and cost-effective technologies as well as fundamental understanding of corrosion deterioration mechanisms.

In emerging countries, on the other hand, there is still a large need to expand infrastructures [3], and thus their main challenge lies in the design of durable new structures (Fig. 2). In these regions, a huge positive sustainability impact can potentially be made if proper construction materials are used, i.e. by combining low environmental footprint of the material with long service lives. Research endeavors have over the last decades increasingly focused on developing new cement types with decreased $\mathrm{CO}_{2}$ emissions $[1,17]$. Concretes produced with these cementitious materials differ from traditional ones in terms of microstructure and chemistry of the pore liquid. In comparison to Portland cement concretes, they typically have lower pore solution $\mathrm{pH}$, lower $\mathrm{pH}$ buffer capacity due to the partial or complete lack of Portlandite, which clearly negatively impairs the protection of the embedded steel from corrosion. On the other hand, these materials may have lower porosity, increased pore tortuosity, or better chloride binding capacity, which slows down chloride transport through the concrete cover and thus may have a beneficial impact on the corrosion performance. The state-of-the-art does, however, not permit reliable performance prognoses of these materials in their actual exposure environments, which clearly handicaps holistic sustainability and life cycle assessments. The poor predictive power $[16,18-22]$ of current models and accelerated testing can be traced to insufficient theoretical grounds (see Sect. 3).

The overarching problem is that in predicting the actual performance of structures built with modern and innovative construction materials and construction processes, one cannot any longer rely on empirical long-term experience from practice. Such experience is available for "traditional" materials, i.e. mainly Portland cement concretes (perhaps also slag concretes) and cold-work hardened reinforcing steels. For all materials introduced after, say 1990, there is very little or no documentation of long-term performance (Fig. 2). Needless to say, for all materials under development or to be developed in the near future, it appears impossible to gain sufficient experience from practical exposure (tests) before approving these materials for large-scale applications in engineering.

In summary, both for existing and for new structures, the challenge clearly lies in making long-term ( $\sim 100$ years) predictions for field performance, based on short-term ( $\sim$ a few months) laboratoryscale testing. Section 3 summarizes the state-of-theart regarding the science and engineering of dealing with RC structures exposed to corrosive environments. A scientific, knowledge-based approach to forecast the durability performance, particularly the corrosion behavior, is clearly needed.

\subsection{Educational challenges}

It is the author's opinion that the current generation of professionals in civil engineering are generally not sufficiently well trained to adequately tackle the technological challenges described above. Interestingly, different analyses by major institutions such as by the National Research Council of the U.S. [15, 23] and by NACE International [6] came to the conclusion that this applies to the entire field of corrosion challenges (Fig. 1), and not only to corrosion of steel in concrete.

Concrete structures are primarily dealt with by civil engineers, who are typically well trained in assessing 
Fig. 2 Technological challenges related to corrosion of steel in concrete are different in different regions in the world. Industrialized countries (a) are mainly challenged to maintain their stock of existing infrastructures, while emerging countries (b) expanding their infrastructures are challenged to design sustainable and durable new structures, where the everincreasing diversity in construction materials and processes does not anymore permit relying on empirical long-term experience (c). d Summarizes the technological challenges highlighting the need for a more science-based approach

\section{Technological challenges}
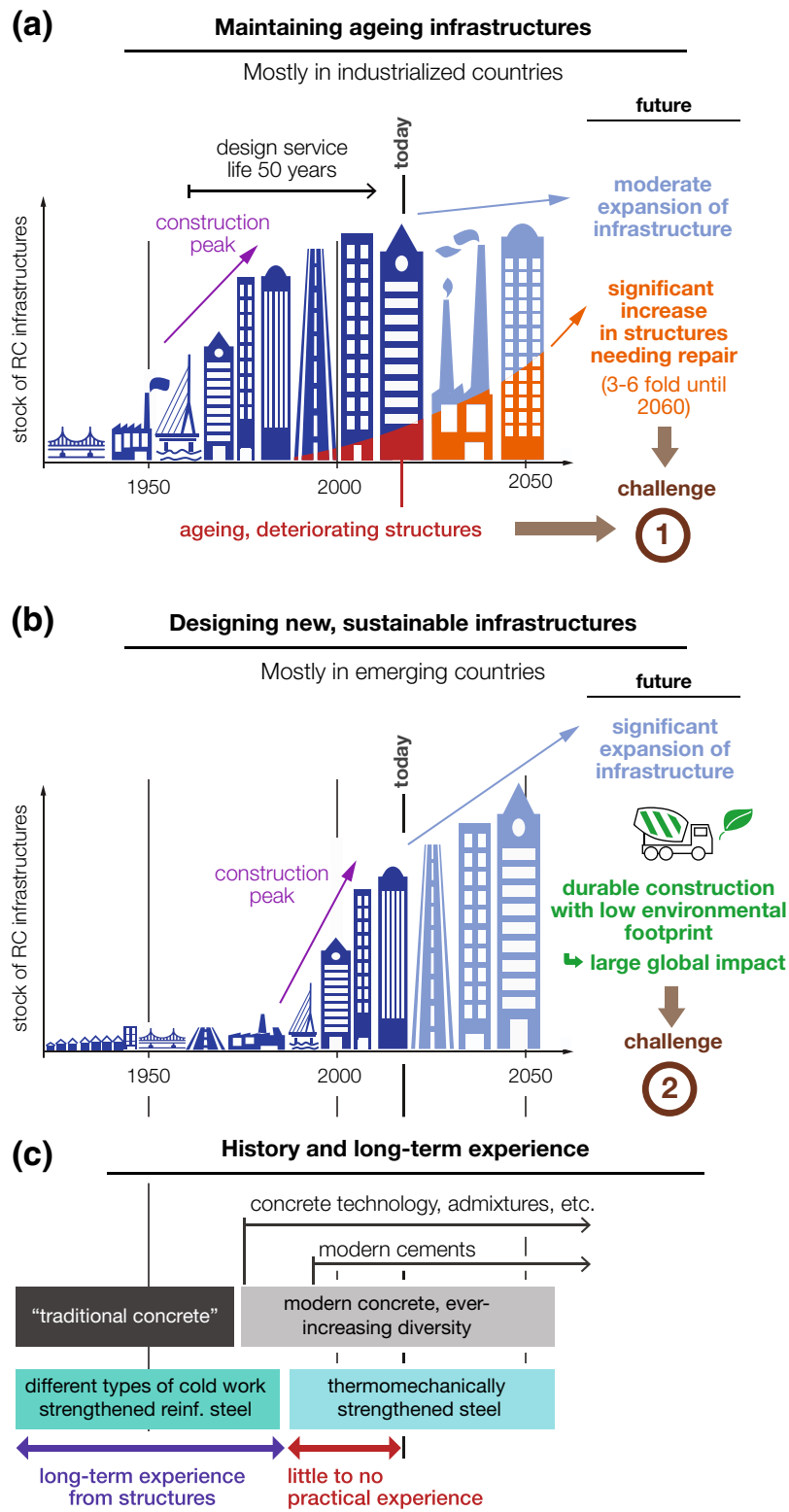

(d) Challenges 
the structural (mechanical) behavior, but have limited education in materials science related matters. Assessing the condition of ageing reinforced and pre-stressed concrete structures as well as specifying cost-efficient repair works are not straightforward and generally present situations where no off-the-shelf-solutions can be used. This is because existing structures differ strongly in terms of materials used, depending on the time of construction [24], regional owner policies or available commercial products [16]. It is also generally recognized that exposure conditions and histories may exhibit significant variability, and that a number of degradation mechanisms may be at hand simultaneously. Corrosion of reinforcing steel and particularly of pre-stressing steel is under certain conditions not visible at the concrete surface, at least not in early stages of corrosion propagation; this presents a severe limitation for traditional routine inspections that are typically done visually [25]. Additionally, condition assessment is also not straightforward due to the large number of destructive and non-destructive test methods available [26-28], some of which are based on relatively simple principles, and some which have more complex theoretical backgrounds. Selecting the right methods and interpreting the results properly, particularly when it comes to assessing the corrosion condition and making an assessment of the future corrosion evolution (e.g. in terms of corrosion rates), requires profound knowledge and mechanistic understanding of concrete durability and corrosion. Regarding the construction of new structures, on the other hand, if performance-based approaches are to be used in order to favor innovative solutions (Fig. 2), the increasing level of complexity in understanding and judging the durability of different systems poses higher demands on the education of civil engineers than the prescriptive approach of current standards.

Figure 3 summarizes groups of professionals needed in order to address the challenges summarized in Fig. 2 on different levels. In view of the large societal and economic impact of RC corrosion (Fig. 1), there is no doubt about the urgent need for experts in the field of corrosion of steel in concrete (in Fig. 3 termed "RC corrosion experts"). Ideally, this group of professionals has profound understanding about corrosion and concrete materials science that is universal enough to be applied to non-standard situations, i.e. situations where purely experience based approaches cannot be used. This group of professionals should also have sufficient background to write codes, standards and technical rules to ensure durability for modern and future commercial products and construction technologies, guarantee proper applications of condition assessment methods, etc. Ideally, these corrosion experts have a university degree in civil engineering, materials science, chemistry, metallurgy, or similar, followed by thorough and prolonged study of a corrosion subject such as in the form of a PhD thesis. The current situation, however, is that there are only relatively few professionals who had this sort of training. Generally, many of the professionals taking the role of "RC corrosion experts" have often no or very little formal education in corrosion, but gained experience through on-the-job-training [23].

This can be traced, among other reasons, to the limited opportunities for specialized education in RC corrosion, which directly results from the decreasing number of university professors, capable of offering research positions in the field and in mentoring and training PhD students (in Fig. 3 termed "RC corrosion scientist"). For example, this may be illustrated by the number of technical university professors, carrying out scientific research and teaching the issue of reinforcing steel corrosion in concrete at their institutions, which in the German speaking part of Europe (Germany, Austria, Switzerland) has decreased from 7 in the early 2000s to 3 by today-due to retirements, followed by replacements of faculty members with expertise in other fields. It is thus the author's opinion that there is a need for creating more faculty positions in the field of corrosion and concrete durability. To enhance transfer of knowledge to engineering, this should preferably be in engineering rather than materials science departments. Additionally, this would ensure a minimum level of corrosion education of future generations of civil engineers as the topic of concrete durability and corrosion could be integrated better in curricula at B.Sc. and M.Sc. level, which is currently rarely the case [23].

It is considered important that not only so-called experts, but also the broad workforce in civil engineering has an improved awareness of corrosion and durability problems, as this is generally needed for consulting, tendering, design, etc. This group of professionals is in Fig. 3 termed "consulting engineer/owner dealing with RC infrastructures", which intends to indicate that not only civil engineers in 


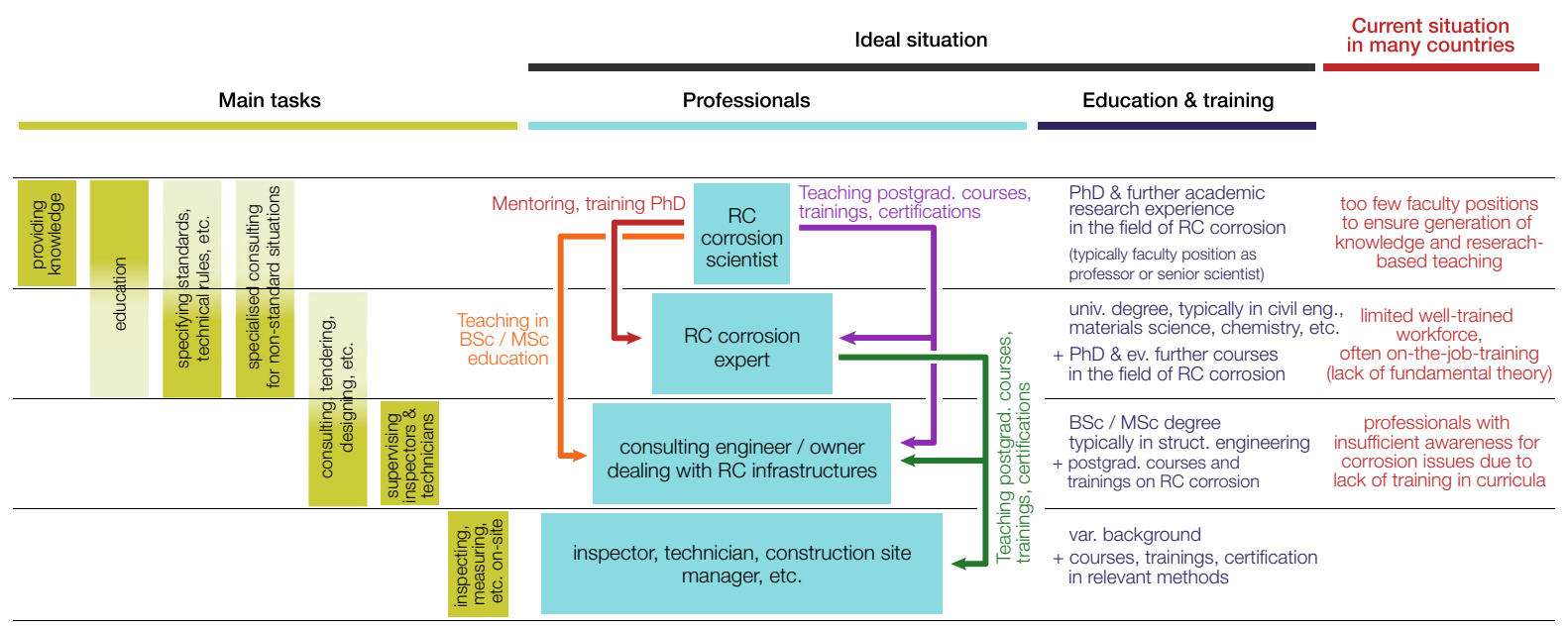

Fig. 3 Different groups of professionals urgently needed in order to tackle the grand challenge of RC infrastructure ageing in industrialized countries and to ensure the design and construction of durable infrastructures in emerging regions. The education ideally needed for the different groups of professionals is also indicated, and the arrows illustrate the

general, but also owners of public or private assets will benefit from increased durability knowledge. Increased awareness would also allow this group of professionals to take more educated decisions about whether or not to involve more specialized corrosion experts in certain situations. The same applies also the last group of professionals shown in Fig. 3, i.e. those working primarily on-site, for instance inspectors (routine inspections on behalf of public or private owners), technicians carrying out certain types of condition assessment measurements, but also site managers-as it is well known that execution has a pronounced influence on the achieved durability [29].

In summary, it is the authors opinion that currently, there is an insufficient number of adequately trained professionals to deal with the grand challenges related to the durability of RC infrastructures. This can be explained by the decreasing and currently low-with respect to the tremendous societal and economic relevance-number of faculty positions at universities capable of leading research projects and educating professionals in the field of corrosion in RC. These positions are not only needed to provide the scientific basis in order to address the technological challenges such as the questions related to novel cementitious materials (see Sect. 2.2), but also to provide more opportunities for training of RC corrosion experts and to integrate the topic of concrete durability and roles that these professionals may take in educating other groups. On the right, the current situation is summarized, which contrasts with the ideal situation and thus highlights the educational challenges that industrialized countries typically face. The figure was developed based on Ref. [23]. RC = reinforced concrete

corrosion in the education of civil engineers at $\mathrm{BSc}$ and MSc level.

\section{State-of-the-art}

3.1 General remarks about corrosion of steel in concrete

Concrete is a porous solid that contains an alkaline liquid phase. In traditional concrete made with Portland cement, the $\mathrm{pH}$ is buffered well above 12.5. This is the undisputed reason why embedded carbon steel, as such thermodynamically unstable in the presence of water, is protected from corrosion [28, 30, 31]. The protection mechanism is the formation of a passive film that reduces the rate of oxidation to a technically negligible level.

Corrosion can be triggered by the ingress of chloride-e.g. due to exposure to seawater or road deicing salts - and/or by carbonation of the concrete [28]. In his work published in 1982, Tuutti [32] proposed the well-known schematic service life model of a RC structure; a modified version of it is shown in Fig. 4. This conceptual model distinguishes two stages: the initiation stage describes the transport of the corrosive agents through the concrete to the steel until conditions are met for corrosion initiation; the 
Fig. 4 Schematic illustration of the life of a reinforced concrete structure, distinguishing the initiation stage, corrosion onset, and the corrosion propagation stage (adapted from Tuutti [32]). Green and red areas indicate where the state-of-the-art is well advanced, and where fascinating research questions still remain open, respectively

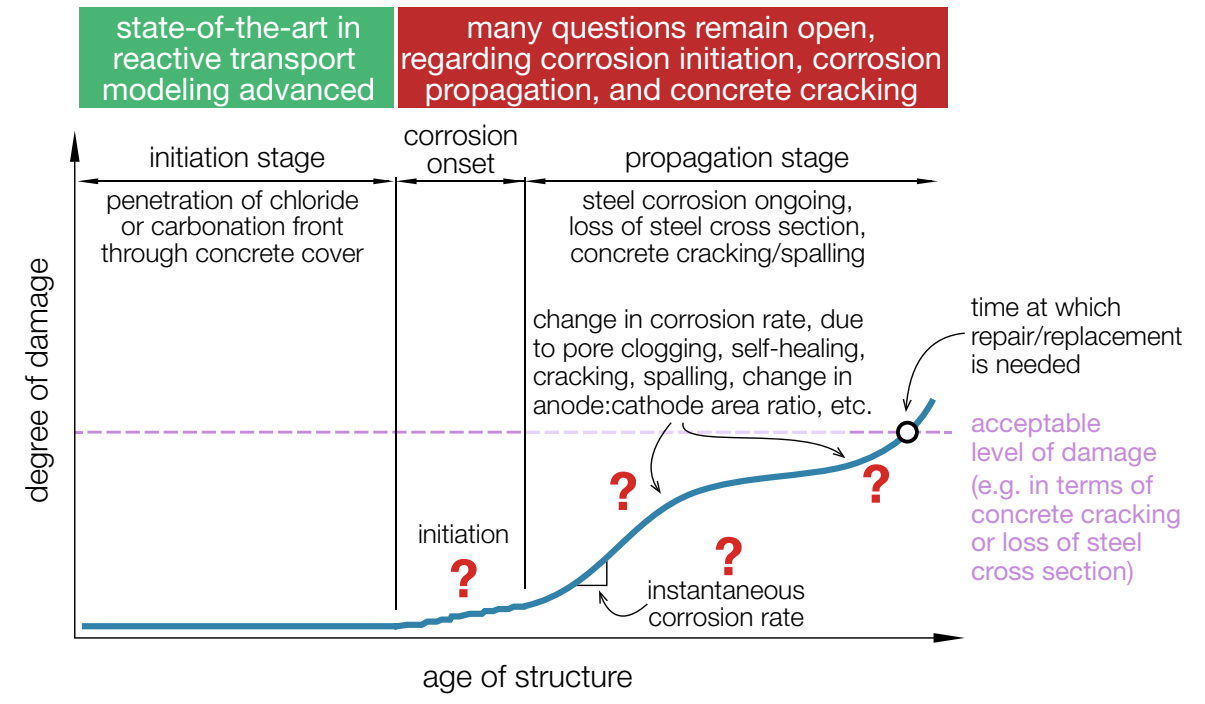

propagation stage describes the process of corrosion and accumulation of related damage until a limit state and thus the end of the service life is reached. Note that corrosion onset is not considered an instant, but rather a period of time [33-36]. Particularly for chlorideinduced corrosion, it is well known that the stable (self-sustaining) growth of anodic sites requires a number of conditions to be fulfilled, such as sufficient supply of chloride ions from the surrounding concrete $[35,37]$. Thus, at early stages of corrosion initiation, the steel may repeatedly repassivate, and further accumulation of chlorides is needed to promote active and stable corrosion. Once corrosion propagates, the kinetics may be affected by a number of factors such as pore clogging due to precipitation of corrosion products or other solid phases and self-healing effects in the case of corrosion in cracked zones [38], that would both reduce the corrosion rate, or by concrete cracking and spalling that would accelerate corrosion. This leads to a non-linear corrosion propagation as schematically shown in Fig. 4. The instantaneous corrosion rate is also affected by seasonal or other changes in exposure environment, such as varying moisture conditions [28]. The limit states for corroding RC structures are the loss of steel sectional area or corrosion-induced cracking of the concrete; both can affect the load bearing capacity and structural integrity, and thus the safety of a structure.

In traditional research, initiation of corrosion due to chlorides and due to carbonation are usually treated separately [28]. Measuring and modeling the penetration of the so-called carbonation front or of chlorides through the concrete has over the last decades received considerable research attention. Reliable methods are available in international standards and allow the quantification of these transport processes through the concrete cover both in laboratory specimens and in engineering structures [28, 39-42]. Additionally, predictive models of different degrees of complexity-ranging from fully empirical to sophisticated, mechanistic models-were proposed and some of them provide reasonably accurate predictions, both for carbonation [43-47] and for chloride transport [42, 44, 48-50]. For more detailed information about reactive transport modeling it is here referred to the cited literature. However, models and methods to predict the penetration of the carbonation front and of chlorides through the concrete cover are here considered relatively well developed, particularly in comparison to the state-of-the-art related to corrosion initiation and corrosion propagation, as reviewed in the next sections.

\subsection{Initiation of reinforcement corrosion}

In the case of carbonation of the concrete, it is normally assumed that corrosion initiates as soon as the carbonation front reaches the reinforcing steel, i.e. once the $\mathrm{pH}$ value of the concrete pore solution approaches neutrality [28]. To predict corrosion onset in the case of chloride-induced corrosion, it has been the concept for many years to define a certain chloride 
threshold value or critical chloride content $\left(C_{\text {crit }}\right)$ as the threshold chloride concentration associated with corrosion onset. Over the last 60 years considerable research efforts have been made to determine the value and/or the distribution of $C_{\text {crit }}$, as reviewed in Ref. [51]. The literature results, however, scatter over several orders of magnitude, and thus offer a poor basis for service life modeling, particularly considering that $C_{\text {crit }}$ is one of the most decisive model input parameters. One reason for the literature scatter is that it is experimentally not straightforward to determine $C_{\text {crit }}$; in fact, the experimental methodology has long been subject to controversial debate in the literature [51]. This was also reflected within the work of RILEM technical committee 235-CTC [52].

The conceptual understanding of $C_{\text {crit }}$ has over many years been that different values for $C_{\text {crit }}$ may be experimentally measured for different cement types, steel grades, etc. However, numerous studies have indicated that effects not systematically related to the materials under study play a major role in corrosion initiation. In fact, the susceptibility to corrosion was found to strongly depend on the local conditions at the steel-concrete interface. These often called "defects" are recognized to offer preferable corrosion initiation sites. Examples are air voids or other macroscopic voids [53, 54], the bleed-water zone at the underside of reinforcement steel [55, 56], or cracks [57]. Regarding the role of voids in corrosion initiation, contradictory results were published in the literature, i.e. air voids at the steel surface were found to present preferential sites for corrosion initiation $[53,54,58]$, while the contrary was observed in other experiments $[34,59]$. In this regard, the moisture conditions within the concrete pore system have recently been identified to play a crucial role [24, 60], but without doubt, more research is needed to clarify the influence of voids on corrosion initiation. Other factors in corrosion initiation are the steel surface condition, e.g. the presence of mill-scale or rust layers [61, 62]. Also metallurgic features such as lattice defects or inclusions are well known to influence initiation of pitting corrosion [63]. With respect to metallurgy, recent studies shed light on the importance of the steel microstructure-as originating from different production processes such as cold-work hardening or thermal strengthening - on the corrosion susceptibility [64-66], a factor that is generally ignored, but may in fact be highly relevant since most of the reinforcing steel from which long- term field experience is available was manufactured with a different process than the steel used today.

While the importance of various local "defects" and "irregularities" at the steel-concrete interface is widely recognized, their relative influence is not well understood. As a result, they are not accounted for in current predictive models. A review [24] of documented properties of steel-concrete interfaces in laboratory specimens and in engineering structures highlighted that the steel-concrete interface is complex, prone to significant variability from one case to another, and that it may be difficult to mimic conditions representative for engineering structures in laboratory specimens. In recognition of this, a test method was recently suggested to measure the statistical distribution of $C_{\text {crit }}$ in samples taken from engineering structures and to assess the effect on corrosion initiation of various local characteristics of the steel-concrete interface that can be found in structural concrete [67].

The poor predictive power of the concept of $C_{\text {crit }}$ may be illustrated with help of results obtained with this test method from a more than 40 year old Swiss road tunnel located in the Alps [59, 68]. Concrete cores of diameter $150 \mathrm{~mm}$, containing a segment of reinforcing steel, were drilled from the ceiling of the tunnel concrete lining that was still free from corrosion, and subsequently tested in the laboratory. The obtained results yielded a probability distribution of $C_{\text {crit }}$, that was for the present purpose fitted with a lognormal distribution (parameters $\lambda=E\left(\ln C_{\text {crit }}\right)=$ $-0.21, \quad \varepsilon^{2}=\operatorname{var}\left(\ln C_{\text {crit }}\right)=0.74$, and first two moments $\mu=E\left(C_{\text {crit }}\right)=0.91 \%$ chloride by weight of cement, $\sigma^{2}=\operatorname{var}\left(C_{\text {crit }}\right)=0.48 \%$ chloride by weight of cement). This was based on 11 concrete cores all sampled within a concrete area of less than $2 \mathrm{~m}^{2}$, thus presumably uniformly exposed and from the same batch of construction materials.

Figure 5 shows the results of a simple prediction of the time to corrosion initiation (all assumptions given in the figure caption). It is apparent that the predicted time to corrosion initiation is dispersed over large time spans. Corrosion-though with a relatively low probability - may start after a few years, but that it may also take many hundreds or even thousands of years without corrosion. On the one hand, this can be explained by the fact that the statistical distribution of $C_{\text {crit }}$, in this case measured on an engineering structure, spans a much wider range than the distributions 


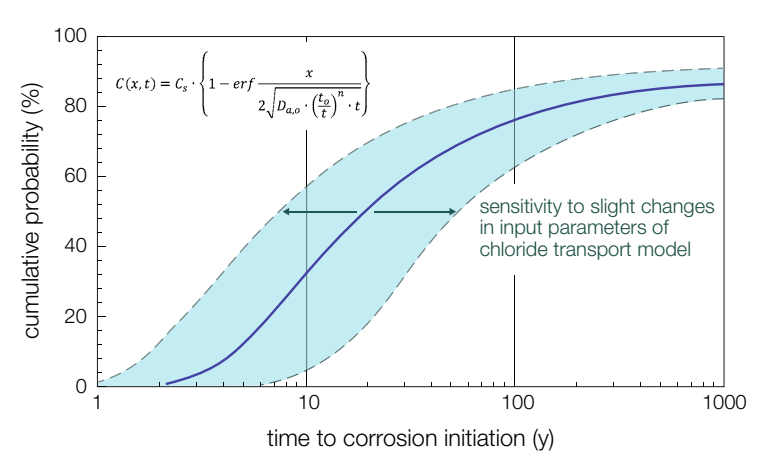

Fig. 5 Example of a prediction of the time to corrosion initiation for realistic statistical distribution of $C_{\text {crit }}$, illustrating the dispersion of the prediction over a wide range and thus highlighting the severe limitations of the current conceptual approach to forecast chloride-induced steel corrosion in concrete. A simple chloride transport model [42, 69] was used to predict $C(x, t)$, i.e. the chloride content at depth $x$ and time $t$, the equation of which is displayed in the figure, and with the following assumptions for the calculations represented by the solid line: apparent chloride diffusion coefficient (at time $t_{\mathrm{o}}$ ) $D_{\mathrm{a}, \mathrm{o}}=10^{-12} \mathrm{~m}^{2} / \mathrm{s}$, reference time $t_{\mathrm{o}}=28$ days, ageing exponent $n=0.4$, cover depth $x=40 \mathrm{~mm}$, chloride content at surface $C_{\mathrm{s}}=3 \%$ chloride by cement weight. The time to corrosion was calculated as the time until the predicted chloride content at the cover depth equals $C_{\text {crit }}$. $C_{\text {crit }}$ was treated as stochastic variable, the distribution of which was obtained from measurements with a novel test method [67] applied to 11 samples taken from within a small concrete surface area $\left(<2 \mathrm{~m}^{2}\right)$ of a $>40$ years old engineering structure [59, 68]. The shaded area illustrates the strong sensitivity of the chloride transport model to the input parameters. The dashed curves result from making the following changes: decreasing/increasing $D_{\mathrm{a}, \mathrm{o}}$ by a factor of 2 , or decreasing/increasing the ageing exponent by $25 \%$, or decreasing/increasing the cover depth by $30 \%$

observed in laboratory specimens (e.g. the data reported in Refs. $[69,70])$. On the other hand, this is a direct result of the fact that the increase in chloride concentrations in concrete tends to slow down with time, which thus amplifies any uncertainties in $C_{\text {crit }}$ when converted into time to corrosion. In other words, it is the unfortunate combination of the two facts, (1) the wide variability of realistic $C_{\text {crit }}$ and (2) the slow increase in chloride concentration at the cover depth after a few decades, which together lead to huge dispersions in predicted service life, such as of the sort of Fig. 5. Figure 5 also illustrates the strong sensitivity of this model approach to input parameters: even small uncertainties in transport coefficients or the cover depth disperse the predicted time to corrosion over as much as one order of magnitude.
Ideally, to facilitate the interpretation and application in engineering practice, a predictive model should exhibit a much steeper probability distribution than the curves shown in Fig. 5. The fact that the prediction is strongly dispersed indicates that the parameter, on which the prediction is essentially based (chloride), does not have a dominating influence on the actual phenomenon of corrosion initiation. In other words: reducing the problem to a mere question of chlorides seems not to provide adequate predictions. Other, also or even more relevant parameters, are overlooked. The common way to deal with this unfortunate situation is to define an acceptable probability of corrosion, rather than to look for better ways to predict corrosion initiation. However, the selection of a specific value for this acceptable failure probability is not straightforward, particularly not for localized corrosion, as has been discussed in more detail in Refs. [71, 72].

As an additional problem complicating the use of the concept of $C_{\text {crit }}$ for service life predictions, it has been experimentally shown that the specimen size affects the susceptibility to pitting corrosion [73-75]. This was explained by the increasing probability for the presence of preferable initiation sites with increasing specimen size. Nevertheless, this "size effect" of corrosion in concrete directly raises the question of the "correct size to be used in service life modeling", i.e. the question of extrapolating small laboratory-scale results to large, real-structure dimensions. This has been addressed in Ref. [71], where it was discussed that the selection of the size used in corrosion predictions should ideally be based on structural considerations, taking into account the load carrying behavior of the actual structural member. A suggestion was also made how $C_{\text {crit }}$ can be translated from one size into another [71, 75]. Finally, taking into account the size effect in corrosion predictions will also give a better understanding of the physical meaning of the acceptable failure probability.

Nevertheless, after now 60 years of intense research, one may conclude that the poor understanding and predictive power of the current concept of $C_{\text {crit }}$ call for a new approach. Reducing the issue of corrosion initiation to a question of chlorides only is an oversimplification of reality and does not permit reliable performance forecasting. 
3.3 Propagation of reinforcement corrosion

\subsubsection{Quantitative models to predict the propagation stage (corrosion kinetics)}

A variety of models have been proposed to predict the corrosion rate of steel in concrete, as reviewed e.g. in Refs. [76, 77]. Some models are simply based on an empirical correlation of the corrosion rate to a relatively easily measureable parameter such as the concrete resistivity, but they were shown to have a poor predictive power [19]. More refined approaches involve finite element or boundary element modeling by relying on mathematical expressions for the anodic and cathodic partial reactions as well as for the ohmic current flow in the electrolyte [78-80]. The polarization behavior of the partial reactions is typically described with Butler-Volmer equations (or simplified, e.g. linearized, relationships) and the corresponding coefficients are generally considered timeinvariant. Nevertheless, it is well known that the kinetics both of the anodic and the cathodic partial reactions can significantly change when conditions at the steel-concrete interface change. Examples are the influence of local changes in electrolyte chemistry ( $\mathrm{pH}$, oxygen concentration, etc.) or half-cell reactions becoming controlled by mass transport [35, 81, 82]. Causes for this may be that the concrete pore system close to the anodic sites becomes blocked by precipitated corrosion products or that the supply of chloride ions to the corrosion pit gets restricted by a limited reservoir of available chloride (release of bound chlorides) [35, 56, 81]. Rigorous descriptions of the transport and precipitation of corrosion products in the pore system and the resulting transport limitations that in turn affect the corrosion kinetics are currently not available. This lack of knowledge presents a serious barrier to developing mechanistic models for the corrosion propagation stage.

\subsubsection{Corrosion-induced concrete cracking}

Precipitation of corrosion products in the concrete pores may give rise to expansive stresses and lead to concrete cracking and spalling. Cracks are undesirable for numerous reasons, e.g. because they promote further ingress of species that may trigger additional deterioration mechanisms. Corrosion-induced cracking is thus a common limit state in service life considerations. Additionally, cracks play a major role in routine inspections of RC structures, which are typically based on visual assessment and where cracks are the only considered indicator of internally ongoing corrosion. However, there are documented cases of reinforcement corrosion that led to structural collapse (due to loss of steel sectional area), but without any outwardly visual signs of such as cracks or rust stains [25]. It is thus essential to know the conditions under which corrosion leads to cracking and to be able to predict at what stage of the corrosion process this occurs.

A well-known reason for delayed cracking is the presence of chlorides, as these strongly increase the solubility of corrosion products [83] and therefore permit migration and diffusion through the pore system and away from the steel. Thus, for chlorideinduced corrosion, precipitation of rust, if any, will thus only occur either distant from the corroding spot (preferably in the internal parts of a structural member [25]) and under conditions not leading to expansive stresses. Precipitation probably also only occurs after relatively high amounts of iron have been released into the concrete pore system, i.e. late in the propagation stage, where already considerable loss of steel cross section has occurred. If corrosion occurs at lower chloride concentrations, i.e. due to carbonation, precipitation of corrosion products is likely to occur earlier, much closer to the steel surface and under conditions that can lead to expansive stresses. This is also favored by the uniform corrosion morphology, which reduces the concrete volume that can accommodate corrosion products. Nevertheless, the fact that already very small amounts of chloride have a pronounced effect on the precipitation of corrosion products [83] implies that the role of chloride should not be neglected in modeling cracking for carbonation-induced corrosion. Even in the absence of chloride exposure, concrete normally contains small amounts of chloride that may enhance the solubility of corrosion products and permit to some extent diffusion and migration away from the steel. Further indication that at least minor amounts of chloride play a role also in carbonation-induced corrosion is the fact that — considering the classical Pourbaix diagram [84] of iron in the absence of chloride-steel would still be passive at the potentials typical for aerated concrete [28] down to $\mathrm{pH}$ values as low as 5 or 6 , which contradicts all field observations. 
A recent analysis [20] of existing models to predict corrosion-induced concrete cracking has indicated that none of the numerous proposed models can reliably predict the time-to-cracking. Typically, the models provided relatively accurate predictions for the experimental results they were fitted to. However, if they are used to model the time-to-cracking for data of other studies, the predictions were found to be poor. One of the reasons is that these models are calibrated with accelerated laboratory tests that are neither representative for real conditions nor comparable to other laboratory tests. Moreover, they use strongly simplified input data to take into account the corrosion rate. As there is a general agreement that the concrete pore structure can accommodate a certain amount of precipitated corrosion products before expansive pressure is exerted $[85,86]$, predictive models typically include a parameter termed "porous zone" or "diffusion zone" which describes an idealized cylindrical void around the steel bar that first needs to be filled with corrosion products before expansive pressure arises [20]. The expansive pressure that finally leads to concrete cracking is usually explained simply by the volume increase of (precipitated) corrosion products by a factor of ca. 2-7 with respect to the originally solid iron [85]. However, several investigations have shown that the corrosion products are deposited around the steel, but that they also penetrate the concrete matrix and precipitate in the pore system far from the steel [87-89].

In short, the conceptual understanding forming the state-of-the-art for modeling corrosion-induced concrete cracking is from a rather global perspective and does not address the fundamental processes in sufficient detail. For instance, the relative kinetics of the rate at which ferrous ions are released at the steel surface (corrosion rate) with respect to the rate of transport into the matrix is crucial in determining the location of precipitation. Under conditions of accelerated testing, e.g. by using impressed currents, the rate of release of ferrous iron is typically several orders of magnitude higher than rates observed in reality. This means that local (super)saturation around the reinforcement steel bar, an important condition for mechanical damage [90, 91], will be reached faster under accelerated corrosion since there is less time for the released ferrous ions to move away than under natural conditions.
Indeed, it is well known that precipitates will only exert expansive stresses if they are forced to grow under confined conditions, such as against pore walls [90-94]. Additionally, this growth must occur under supersaturated conditions, which dictate the crystallization pressure at the pore scale. Finally, the macroscopic stress will only arise once a certain volume fraction of pores is filled by the crystallization compound. The common approach simply based on a volume expansion is thus a strongly simplified view of the problem and it is suggested that future research endeavors to predict corrosion-induced concrete cracking take into account the dual thermodynamic and poromechanical nature of expansive pressure and macroscopic stress.

\subsection{Condition assessment of engineering structures}

\subsubsection{General remarks}

Many considerable improvements were made over the past decades with respect to non-destructive test methods for reinforced and pre-stressed concrete structures. Various well-proven test methods are available such as for measuring concrete cover depths or for locating reinforcing steel and tendons even at large depths [95], or for the quantification of durability indicating parameters such as the specific electrical concrete resistivity [96]. The main challenges in assessing the condition of existing concrete structures are the detection of corrosion and the quantification of the rate of corrosion, as well as the condition of prestressing steel, particularly in post-tensioned structures inside ducts.

\subsubsection{Detecting corrosion initiation}

Actively corroding steel in concrete can generally be reliably distinguished from passive steel by means of potential measurements [97]. There exists a number of different national and international standards for potential mapping on concrete structures [98-100], and although they differ in philosophy, they generally permit locating the zones where corrosion is actively on-going. It is considered a major success that this method was introduced to engineering practice and forms today, in many countries, an important part of assessing the condition of concrete structures, 
providing the basis for the design and scheduling of maintenance works.

A major factor driving the costs of the application of potential mapping and other non-destructive test methods in practice is the limited accessibility to structures, e.g. the undersides of bridge girders (Fig. 6), which demands costly equipment and laborious procedures to perform measurements on the respective concrete surfaces. It is expected that novel approaches utilizing drones and robots [101] will over the coming years solve this problem and thus greatly reduce the cost of potential mapping and other nondestructive condition assessment methods, thereby further promoting their application (compare Sect. 3.4.5).

\subsubsection{Instantaneous corrosion rate measurements}

A major challenge presents the non-destructive, reliable determination of the instantaneous corrosion rate, particularly in localized corrosion, where relatively high corrosion rates can occur due to the galvanic element formed between small anodic and comparatively large cathodic areas. Many electrochemical measurement procedures exist [7], most of them relying on the polarization resistance, $R_{\mathrm{p}}$. The socalled linear polarization resistance method (LPR) makes use of the inverse proportionality between $R_{\mathrm{p}}$ and the instantaneous corrosion rate, known as the Stern-Geary equation [102], which was derived under several assumptions, one of them being the uniform corrosion morphology [103]. Despite this, the LPR method has since the late 1970 s been widely applied to macro-cell corrosion of steel in concrete both in research and practice [104-108], and even commercial devices are available. Given the sometimes large discrepancies between the results of the LPR method and other techniques (e.g. gravimetric measurements), researchers have been concerned with a variety of possible error sources. One of the most frequently addressed issue is that of "current confinement" [107-109] where-with help of refined instrumentation (guard rings) - it is attempted to manipulate the flow of current through the concrete in order to control

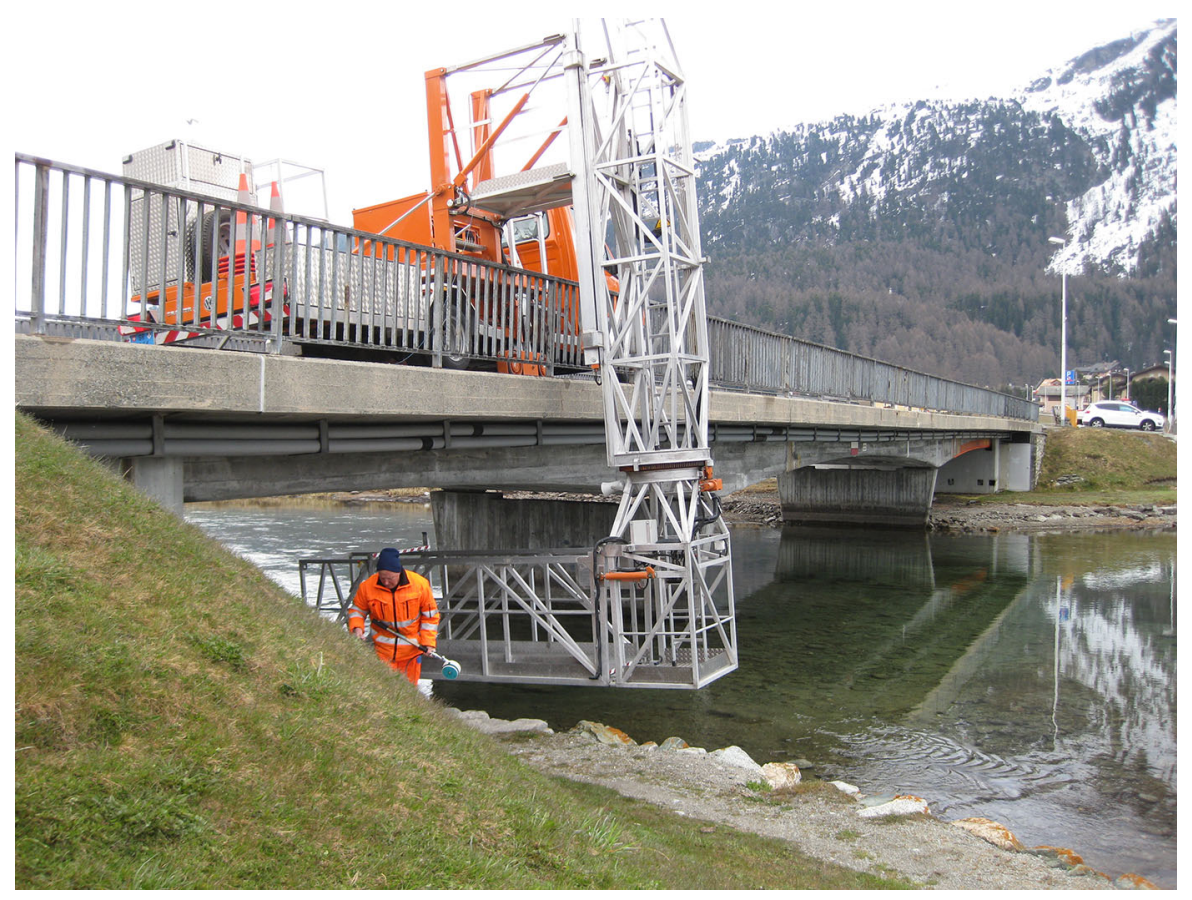

Fig. 6 Example of the inspection (here: potential mapping) of the underside of a bridge girder, illustrating that costly equipment and laborious procedures are needed to perform the measurements on the concrete surface of interest. This is one of the main factors driving the costs of condition assessments.
Future use of robots and drones will considerably reduce the time and equipment needed to apply non-destructive test methods on engineering structures and thus enhance the quality (e.g. spatial resolution) and quantity of information about the (corrosion) condition of structures 
the "polarized steel surface area", knowledge of which then supposedly allows conversion of the determined corrosion current into a current density ( $\sim$ corrosion rate). The benefit of confinement techniques, however, is subject to controversial discussions in the literature [107].

Surprisingly, little attention seems however to have been given to the fact that the Stern-Geary equation is applied to pronounced situations of localized corrosion, although it is explicitly only valid for uniform corrosion. This fundamental discrepancy was discussed in recent publications by the present author [110, 111]. While a relationship between $R_{\mathrm{p}}$ and the corrosion rate may still exist, it must be acknowledged that this is a purely empirical one, which can be traced to the fact that well-defined mixed potentials according to theory of Wagner and Traud [103] do simply not exist in macro-cell corrosion and thus, the position of the reference electrode in measuring setup, and hence the recorded signal, becomes arbitrary [110, 111]. Further research should thus aim at developing alternative methods to quantify the corrosion rates, preferentially based on sound corrosion theory. If empirical approaches are to be used, it is considered crucial to provide more detailed information about the conditions under which such methods provide adequate results.

The need for methods allowing to reliably quantify the rate of local loss of steel sectional area in corroding concrete structures will rise over the coming years and decades. This is due to the increase in the fraction of engineering structures starting to corrode and needing repair. Reliable data on corrosion rates will permit scheduling maintenance works in a more refined manner than with today's relatively conservative approaches. This will be needed in order to dilute the expected increase in structures needing repair simultaneously [14] and thus diminish the economic impact of infrastructure aging.

\subsubsection{Pre-stressed and post-tensioned concrete}

Finally, a major challenge is the assessment of the condition of steel tendons in pre-stressed and posttensioned structures. Poor grouting of ducts (i.e. the presence of voids), chloride-containing grouts, or perforated ducts permitting penetration of corrosive species from the environment to the steel strands are well-known factors that may seriously affect the corrosion condition of steel tendons [28]. While advances have been made with respect to nondestructive inspection methods [112-114], the reliable assessment of pre-stressed and post-tensioned concrete structures still poses difficulties in many practical situations.

\subsubsection{Structural health monitoring and automated inspection}

A number of sensors have been developed over the past years to measure durability-relevant parameters on engineering structures. This includes embeddable reference electrodes [115], sensors for chloride concentrations [116-119] and $\mathrm{pH}$ values [120-122] of the concrete pore solution, and sensors for the measurement of concrete resistivity or galvanic currents [123]. Although the use of such sensors in the context of monitoring has early been demonstrated to provide valuable data $[124,125]$, there is to-date no widespread application of these sensors in engineering practice. Increasing their use as embedded probes in engineering structures in the context of structural health monitoring would, combined with the advances made in information technology, data transmission, etc., would permit to generate large amounts of valuable durability-related data. Semi-automated systems would be needed to process and pre-analyse the data in order to provide useful information for engineers. It is believed that such approaches would permit to better asses the condition of infrastructures, namely by following the evolution over time of different corrosion-relevant parameters.

As mentioned above, also the inspections of structures performed at regular time-intervals would benefit strongly from automation, namely through utilizing drones and robots [101, 126, 127]. Drones may be used for recording images of the concrete surface (without touching the structure), followed by automated image analyses, e.g. for crack detection. Additionally, if able to touch the concrete, climbing robots and flying drones may also perform electrochemical and other non-destructive measurements on structures, which is of particular advantage in difficult to access areas of structural members (an example is shown in Fig. 6).

The author believes that automating electrochemical measurements combined with image-based inspections of engineering structures will considerably 
reduce the costs related to the conventional approach of condition assessment and corrosion inspection. This is because flying drones and climbing robots render heavy equipment such as lifting platforms and mobile inspection trucks obsolete. Furthermore, they reduce the personnel involved in the measurement, and speed up the measurement by reducing much of the manual work (marking the grid, documenting visual appearances, etc.), which reduces the costs further. In addition to reducing costs, manpower as well as measuring and processing time, the use of automated monitoring and inspections will also reduce the negative impact on the availability of the road networks for the end-user.

Finally, automating inspections will also make it easier to apply non-destructive testing in practice. This will favor its integration in routine inspections of reinforced concrete structures. In contrast to conventional routine inspections relying essentially on visual assessments, this permits the detection of corrosion in early stages, i.e. when the corrosion damage is still small and can be repaired more cost-efficient than at later stages. This will lead to additional cost-savings for the owners, such as public owners of infrastructures, and thus in the end for society.

\section{Concluding remarks and opportunities}

This paper has highlighted a number of societal, economic, technological, and educational challenges related to corrosion of steel in concrete. On the one hand, the enormous financial impact of infrastructure corrosion was illustrated, which, on the other hand seems to be inadequately balanced by educational and scientific research activities. Based on this, as well as on a review of the state-of-the-art, several opportunities for research and education were identified as outlined below:

- Societal and economic opportunities The tremendous societal relevance of the progressive infrastructure ageing and corrosion presents a unique opportunity to industrialized countries for maintaining or improving their competitiveness. Mastering the here highlighted technological challenges better in the future than today would permit making significant financial savings and therefore free resources, which will increasingly be bound in infrastructure maintenance, for other societally relevant purposes.

- Educational opportunities The practically nonexistent formalized corrosion education of civil engineers and other professionals working with reinforced concrete infrastructures presents an opportunity for universities and other educational institutions as well as professional associations to play a lighthouse role in this field.

- Technological opportunities The main technological challenges (Fig. 2) are on the one hand to design durable new structures, i.e. to reliably predict the long-term corrosion performance of RC structures in their actual environments, particularly for modern materials and in the absence of long-term experience. On the other hand, there is an ever-increasing need to cost-effectively maintain existing, ageing RC structures, i.e. to abandon conservative, experience-based decision taking and instead move towards knowledge based selection and design of repair actions. Opportunities are:

1. Favoring innovative solutions-both for the maintenance of existing and the design of new structures-through abandoning prescriptive approaches and instead use performancebased approaches. To reach this aim, however, substantial improvements in service life modeling still need to be made.

2. Embracing the technology of structural health monitoring by installing durability sensors on structures, combined with semi-automated analysis of the large amount of produced data, presents a major opportunity for refined condition assessments of structures, but also gaining experience with modern systems in different exposure conditions.

3. Innovative inspection methods: A major potential is seen in enhancing routine inspections by enriching them with the application of non-destructive test methods on structures with help of flying drones and climbing robots.

- Scientific opportunities The following issues (Fig. 4) present major areas where improvements of the state-of-the-art are not only urgently needed, but will also permit making the most significant impact in tackling the highlighted technological challenges: 
1. A major research opportunity is seen in investigating the steel-concrete interface and in understanding the role of the many different local characteristics in corrosion initiation. This is currently addressed in RILEM TC 262-SCI [128], created in 2014, but more research efforts are certainly needed to make the leap forward needed in this regard.

2. Recent advances in reactive transport modeling and poromechanics present fascinating opportunities for tackling the problem of predicting corrosion-induced concrete cracking and for predicting corrosion propagation in concrete, i.e. taking into account effects such as concentration polarization of the steel, pore clogging and crack self-healing in the concrete, etc.

3. Further improvements are still to be made with respect to non-destructive condition assessment methods, particularly with respect to reliably determining corrosion rates on engineering structures and assessing the corrosion state of pre-stressed and post-tensioned concrete structures.

\footnotetext{
Acknowledgements I would like to thank all colleagues with whom I have collaborated over the last 10 years, i.e. since I decided to settle in the field of corrosion of steel in concrete. These rich collaborations have certainly played a significant role in now being awarded the RILEM Robert L'Hermite Medal. First and foremost, I am deeply grateful to Professor Dr. Bernhard Elsener who has been-in changing roles-my mentor, supervisor, collaborator, and colleague during my entire career in this field. Further thanks are due to Professor Dr. Robert J. Flatt who is a great scientist and supporting colleague and to Prof. Dr. Mette R. Geiker with whom I have the pleasure to collaborate in RILEM TC 262-SCI. I would also like to express my thanks to Dr. Markus Büchler for the many intensive and controversial discussions about all possible aspects of corrosion. Further thanks are due to many other colleagues from whom I have learnt and with whom I shared making steps ahead or who supported me in one way or another. This includes Prof. Dr. Rob Polder, Dr. Karla Hornbostel, Dr. Claus K. Larsen, Prof. Øystein Vennesland, Prof. Dr. Christoph Gehlen, Prof. Dr. Raoul François, Prof. Dr. Nicolas Roussel, Prof. Dr. Roar Myrdal, Prof. Dr. Anders Rønnquist, Dr. Sylvia Kessler, Dr. Maria Cruz Alonso, Prof. Dr. Alberto Sagüés, Prof. Dr. Carolyn Hansson, Prof. Dr. Chris Page, Prof. Dr. Luca Bertolini, Dr. Jacques Marchand, Prof. Dr. Walter Kaufmann, Dr. Fabrizio Moro, Prof. Dr. Burkan Isgor, and Prof. Dr. Alexander Michel. I also acknowledge the work of present and former corrosion $\mathrm{PhD}$ students and collaborators at ETH Zurich: Yurena Seguí Femenias, Carolina Boschmann, Ana Vallejo Vitaller, Matteo Stefanoni, Dr. Zhidong Zhang, Dr. Wei Shi, Asel Maria Aguilar
}

Sanchez, Abhishek Jain, Lucas Michel, Federico MartinelliOrlando, Patrick Pfändler, Matthias Wagner, Heinz Richner, Andreas Reusser, Gabriele Peschke, and Andrea Louys. Thanks are also due to the team of the Swiss Society for Corrosion Protection. I also acknowledge the agencies and institutions financing my work, particularly the Swiss National Science Foundation, the Swiss Federal Roads Office, the Norwegian Public Roads Administration, the Research Council of Norway, as well as ETH Zurich, the Norwegian University of Science and Technology, and the Swiss Society for Corrosion Protection. Finally, and perhaps most importantly, my thanks are due to my wife Dr. Vanessa Angst-Nicollier as well as my lovely children Elin Hanna, Oliver Johan, and Manuel Henrik-who, in wondrous ways, simultaneously empty and fill up my energy supplies when I am not working with corrosion.

\section{References}

1. Flatt RJ, Roussel N, Cheeseman CR (2012) Concrete: an eco material that needs to be improved. J Eur Ceram Soc 32(11):2787-2798

2. World Business Council for Sustainable Development, Cement Sustainability Initiative

3. Schwab K (2017) The global competitiveness report 2016-2017. World Economic Forum, Cologny

4. British Cement Association (1997) Development of an holistic approach to ensure the durability of new concrete construction. British Cement Association, Crowthorne

5. Fédération Internationale du Béton (fib) (2011) fib bulletin no. 59: Condition control and assessment of reinforced concrete structures exposed to corrosive environments. Fédération Internationale du Béton (fib)

6. Koch GH, Brongers MPH, Thompson NG, Virmani YP, Payer JH (2002) Corrosion costs and preventive strategies in the United States. Mater Perform (Suppl) 42:1-12

7. McCafferty E (2010) Introduction to corrosion science. Springer, Berlin

8. Kruger J (2011) Cost of metallic corrosion. In: Revie RW (ed) Uhlig's corrosion handbook, 3rd edn. Wiley, New Jersey, pp 15-20

9. Hansson CM (2011) The impact of corrosion on society. Metall Mater Trans A 42A:2952-2962

10. Xu X, Bishop EE, Kennedy SM, Simpson SA, Pechacek TF (2015) Annual healthcare spending attributable to cigarette smoking: an update. Am J Prev Med 48(3): 326-333

11. Hammond R, Levine R (2010) The economic impact of obesity in the United States. Diabetes Metab Syndr Obes Targets Ther 3:285-295

12. Smith AB, Katz RW (2013) US billion-dollar weather and climate disasters: data sources, trends, accuracy and biases. Nat Hazards 67(2):387-410

13. NACE International (2012) A NACE International White Paper on "Corrosion Control Plan for Bridges". NACE International, Houston

14. Polder RB, Peelen WHA, Courage WMG (2012) Nontraditional assessment and maintenance methods for aging concrete structures-technical and non-technical issues. Mater Corros 63(12):1147-1153 
15. National Academy of Sciences (2011) Research opportunities in corrosion science and engineering. Washington DC

16. Angst UM, Hooton RD, Marchand J, Page CL, Flatt RJ, Elsener B, Gehlen C, Gulikers J (2012) Present and future durability challenges for reinforced concrete structures. Mater Corros 63(12):1047-1051

17. Habert G (2013) Environmental impact of Portland cement production. In: Pacheco-Torgal F, Jalali S, Labrincha J, John VM (eds) Eco-efficient concrete. Woodhead Publishing Series in Civil and Structural Engineering. Woodhead Publishing, Cambridge, pp 3-25

18. Otieno MB, Beushausen HD, Alexander MG (2011) Modelling corrosion propagation in reinforced concrete structures-a critical review. Cem Concrete Compos 33(2):240-245

19. Hornbostel K, Larsen CK, Geiker MR (2013) Relationship between concrete resistivity and corrosion rate-a literature review. Cem Concrete Compos 39:60-72

20. Jamali A, Angst U, Adey B, Elsener B (2013) Modeling of corrosion-induced concrete cover cracking: a critical analysis. Constr Build Mater 42:225-237

21. Sánchez AN, Saguiés AA (2014) Some open issues in forecasting corrosion risk of steel in concrete. Corrosion 70(11):1148-1156

22. Galan I, Glasser FP (2015) Chloride in cement. Adv Cem Res 27(2):63-97

23. Scully JR, Harris WL (2012) Opportunities and challenges in corrosion education: review of a National Research Council assessment. Electrochem Soc Interface 21:67-71

24. Angst UM, Geiker MR, Michel A, Gehlen C, Wong H, Isgor OB, Elsener B, Hansson CM, François R, Hornbostel K, Polder R, Alonso MC, Sanchez M, Correia MJ, Criado M, Sagüés A, Buenfeld N (2017) The steel-concrete interface. Mater Struct 50(2):143

25. Angst U, Elsener B, Jamali A, Adey B (2012) Concrete cover cracking owing to reinforcement corrosion-theoretical considerations and practical experience. Mater Corros 63(12):1069-1077

26. Breysse D (2012) Non-destructive assessment of concrete structures: reliability and limits of single and combined techniques, State-of-the-Art Report of the RILEM Technical Committee 207-INR. RILEM/Springer, Berlin

27. Maierhofer C, Reinhardt H-W, Dobmann G (2010) Nondestructive evaluation of reinforced concrete structures. Woodhead Publishing, Cambridge

28. Bertolini L, Elsener B, Pedeferri P, Redaelli E, Polder RB (2013) Corrosion of steel in concrete: prevention, diagnosis, repair. WILEY-VCH, London

29. Geiker MR (2012) On the importance of execution for obtaining the designed durability of reinforced concrete structures. Mater Corros 63(12):1114-1118

30. Page CL (1975) Mechanism of corrosion protection in reinforced concrete marine structures. Nature 258: 514-515

31. Page CL, Treadaway KWJ (1982) Aspects of the electrochemistry of steel in concrete. Nature 297:109-114

32. Tuutti K (1982) Corrosion of steel in concrete. Dissertation. Lund University, Sweden

33. Andrade C (2003) Determination of the chloride threshold in concrete. In: Cigna R, Andrade C, Nürnberger U, Polder
R, Weydert R, Seitz E (eds) COST Action 521, final report "Corrosion of steel in reinforced concrete structures", pp 101-111

34. Angst UM, Elsener B, Larsen CK, Vennesland Ø (2011) Chloride induced reinforcement corrosion: electrochemical monitoring of initiation stage and chloride threshold values. Corros Sci 53(4):1451-1464

35. Angst U, Elsener B, Larsen CK, Vennesland Ø (2011) Chloride induced reinforcement corrosion: rate limiting step of early pitting corrosion. Electrochim Acta 56(17):5877-5889

36. Boubitsas D, Tang L (2015) The influence of reinforcement steel surface condition on initiation of chloride induced corrosion. Mater Struct 48(8):2641-2658

37. Pourbaix A (1984) Localized corrosion: behaviour and protection mechanisms. In: Proceedings of conference on "corrosion chemistry within pits, crevices and cracks", Teddington, Middlesex, pp 1-15

38. Vennesland O, Gjorv OE (1981) Effect of cracks in submerged concrete sea structures on steel corrosion. Mater Perform 20(8):49-51

39. European Committee for Standardization (2006) European Standard EN 14630: Products and systems for the protection and repair of concrete structures - test methodsdetermination of carbonation depth in hardened concrete by the phenolphthalein method. European Committee for Standardization

40. RILEM TC 178-TMC (2002) Analysis of total chloride content in concrete-recommendation. Mater Struct 35(253):583-585

41. ASTM International (2012) ASTM C1152 standard test method for acid-soluble chloride in mortar and concrete. ASTM International, West Conshohocken

42. Tang L, Nilsson L-O, Basheer MPA (2012) Resistance of concrete to chloride ingress: testing and modelling. CRC Press, Boca Raton

43. Galan I, Andrade C (2009) Comparison of carbonation models. University of Minho, Guimarães

44. Jensen MM, Johannesson B, Geiker MR (2014) Framework for reactive mass transport: phase change modeling of concrete by a coupled mass transport and chemical equilibrium model. Comput Mater Sci 92:213-223

45. Bo Y, Di C, CheSi S, HaiXin W (2014) Comparison of prediction models for concrete carbonation. Adv Mater Res 842:87-90

46. Silva A, Neves R, de Brito J (2014) Statistical modelling of carbonation in reinforced concrete. Cem Concrete Compos 50:73-81

47. von Greve-Dierfeld S, Gehlen C (2016) Performance based durability design, carbonation part 1-benchmarking of European present design rules. Struct Concrete 17(3):309-328

48. Samson E, Marchand J, Beaudoin JJ (1999) Describing ion diffusion mechanisms in cement-based materials using the homogenization technique. Cem Concrete Res 29(8):1341-1345

49. Pradelle S, Thiery M, Baroghel-Bouny V (2016) Comparison of existing chloride ingress models within concretes exposed to seawater. Mater Struct 49(11): 4497-4516 
50. Nilsson L-O, Sandberg P, Poulsen E, Tang L, Andersen A, Frederiksen JM (1997) HETEK-a system for estimation of chloride ingress into concrete, theoretical background (report no. 83). Road Directorate, Denmark, Ministry of Transport

51. Angst U, Elsener B, Larsen CK, Vennesland Ø (2009) Critical chloride content in reinforced concrete-a review. Cem Concrete Res 39(12):1122-1138

52. RILEM technical committee 235-CTC (2009-2015) Corrosion initiating chloride threshold concentrations in concrete

53. Reddy B (2001) Influence of the steel-concrete interface on the chloride threshold level. $\mathrm{PhD}$ thesis, Imperial College, London

54. Buenfeld NR, Glass GK, Reddy B, Viles RF (2004) Process for the protection of reinforcement in reinforced concrete, US Patent $6,685,822$ B2

55. Horne AT, Richardson IG, Brydson RMD (2007) Quantitative analysis of the microstructure of interfaces in steel reinforced concrete. Cem Concrete Res 37(12):1613-1623

56. Angst U (2011) Chloride induced reinforcement corrosion in concrete; concept of critical chloride content-methods and mechanisms. PhD Thesis. Norwegian University of Science and Technology, NTNU. Trondheim, Norway

57. Francois R, Arliguie G (1999) Effect of microcracking and cracking on the development of corrosion in reinforced concrete members. Mag Concrete Res 51(2):143-150

58. Nygaard PV (2003) Effect of steel-concrete interface defects on the chloride threshold for reinforcement corrosion. MSc Thesis, Denmark

59. Angst U, Wagner M, Elsener B, Leemann A, Nygaard PV (2016) Method to determine the critical chloride content of existing reinforced structures, VSS report no. 677. Swiss Federal Roads Office, Berne, Switzerland (in German)

60. Hornbostel K, Angst U, Elsener B, Larsen C, Geiker M (2015) On the limitations of predicting the ohmic resistance in a macro-cell in mortar from bulk resistivity measurements. Cem Concrete Res 76:147-158

61. Li L, Sagüés AA (2001) Chloride corrosion threshold of reinforcing steel in alkaline solutions-open-circuit immersion tests. Corrosion 57(1):19-28

62. Mammoliti LT, Brown LC, Hansson CM, Hope BB (1996) The influence of surface finish of reinforcing steel and $\mathrm{pH}$ of the test solution on the chloride threshold concentration for corrosion initiation in synthetic pore solutions. Cem Concrete Res 26(4):545-550

63. Suter T, Böhni H (1998) Microelectrodes for studies of localized corrosion processes. Electrochim Acta 43(19-20):2843-2849

64. Angst UM, Elsener B (2015) Forecasting chloride-induced reinforcement corrosion in concrete-effect of realistic reinforcement steel surface conditions. In: Proceedings 4th international conference on concrete repair, rehabilitation and retrofitting (ICCRRR), Leipzig, Germany

65. Nair SAO, Pillai RG (2016) Effect of phase distributions on the corrosion of Quenched and Self-Tempered (QST) steel rebars. In: Proceedings of 70th RILEM week and international conference on materials, systems and structures in civil engineering (August 15-29, 2016), Lyngby, Denmark
66. Rivera-Corral JO, Fajardo G, Arliguie G, Orozco-Cruz R, Deby F, Valdez P (2017) Corrosion behavior of steel reinforcement bars embedded in concrete exposed to chlorides: effect of surface finish. Constr Build Mater 147:815-826

67. Angst UM, Boschmann C, Wagner M, Elsener B (2017) Experimental protocol to determine the chloride threshold value for corrosion in samples taken from reinforced concrete structures. J Vis Exp. https://doi.org/10.3791/56229

68. Angst UM, Elsener B (2016) In: ACI Special Publication "Chloride limits and thresholds for concrete containing supplementary cementitious materials (SCM's)" (SP 308). American Concrete Institute, pp 1-12

69. (2006) fib bulletin No. 34: Model code for service life design. International Federation for Structural Concrete (fib), Lausanne, Switzerland

70. Breit W (2001) Critical corrosion inducing chloride content-state of the art and new investigation results. In: Betontechnische Berichte 1998-2000. Verein Deutscher Zementwerke e.V. (VDZ), Düsseldorf

71. Angst U, Rønnquist A, Elsener B, Larsen CK, Vennesland $\varnothing$ (2011) Probabilistic considerations on the effect of specimen size on the critical chloride content in reinforced concrete. Corros Sci 53(1):177-187

72. Gulikers JJW (2008) A simplified and practical approach regarding design for durability of reinforced concrete structures based on probabilistic modeling of chloride ingress. In: Proceedings of 2nd international conference on concrete repair, rehabilitation and retrofitting (ICCRRR), pp 325-329

73. Li L, Saguiés AA (2004) Chloride corrosion threshold of reinforcing steel in alkaline solutions-effect of specimen size. Corrosion 60(2):195-202

74. Keßler S, Angst U, Zintel M, Gehlen C (2015) Defects in epoxy coated reinforcement and their impact on the service-life of a concrete structure. Struct Concrete 16:398-405

75. Angst UM, Elsener B (2017) The size effect in corrosion greatly influences the predicted life span of concrete infrastructures. Sci Adv 3(8):e170075

76. Raupach M (2006) Models for the propagation phase of reinforcement corrosion-an overview. Mater Corros 57(8):605-613

77. Otieno M, Beushausen H, Alexander M (2012) Prediction of corrosion rate in reinforced concrete structures-a critical review and preliminary results. Mater Corros 63(9):777-790

78. Kranc SC, Sagüés AA (2001) Detailed modeling of corrosion macrocells on steel reinforcing in concrete. Corros Sci 43(7):1355-1372

79. Isgor OB, Razaqpur AG (2006) Modelling steel corrosion in concrete structures. Mater Struct 39(3):291-302

80. Warkus J, Raupach M (2010) Modelling of reinforcement corrosion-geometrical effects on macrocell corrosion. Mater Corros 61(6):494-504

81. Page CL, Havdahl J (1985) Electrochemical monitoring of corrosion of steel in microsilica pastes. Mater Struct 18:41-47

82. Glass GK, Page CL, Short NR (1991) Factors affecting the corrosion rate of steel in carbonated mortars. Corros Sci 32(12):1283-1294 
83. Sagoe Crentsil KK, Glasser FP (1993) Green rust, iron solubility and the role of chloride in the corrosion of steel at high pH. Cem Concrete Res 23(4):785-791

84. Pourbaix M (1963) Atlas d'équilibres électrochimiques. Centre Belge d'Etude de la Corrosion CEBELCOR, Gauthier-Villars \& Cie, Paris

85. Liu YP, Weyers RE (1998) Modeling the time-to-corrosion cracking in chloride contaminated reinforced concrete structures. ACI Mater J 95(6):675-681

86. Michel A, Pease BJ, Geiker MR, Stang H, Olesen JF (2011) Monitoring reinforcement corrosion and corrosioninduced cracking using non-destructive $\mathrm{x}$-ray attenuation measurements. Cem Concrete Res 41(11):1085-1094

87. Glasser FP, Sagoe Crentsil KK (1989) Steel in concrete: part 2-electron-microscopy analysis. Mag Concrete Res 41(149):213-220

88. Küter A (2010) Management of reinforcement corrosiona thermodynamic approach. $\mathrm{PhD}$ thesis, Technical University of Denmark

89. Wong HS, Zhao YX, Karimi AR, Buenfeld NR, Jin WL (2010) On the penetration of corrosion products from reinforcing steel into concrete due to chloride-induced corrosion. Corros Sci 52(7):2469-2480

90. Scherer GW (1999) Crystallization in pores. Cem Concrete Res 29(8):1347-1358

91. Flatt RJ, Caruso F, Sanchez AMA, Scherer GW (2014) Chemomechanics of salt damage in stone. Nat Commun 5:4823

92. Flatt RJ (2002) Salt damage in porous materials: how high supersaturations are generated. J Cryst Growth 242(3-4):435-454

93. Steiger M (2005) Crystal growth in porous materials- I: the crystallization pressure of large crystals. J Cryst Growth 282(3-4):455-469

94. Steiger M (2005) Crystal growth in porous materials-II: influence of crystal size on the crystallization pressure. J Cryst Growth 282(3-4):470-481

95. Deutsche Gesellschaft für Zerstörungsfreie Prüfung DGZfP (2014) B2: Merkblatt zur zerstörungsfreien Betondeckungsmessung und Bewehrungsortung an Stahlund Spannbetonbauteilen. Deutsche Gesellschaft für Zerstörungsfreie Prüfung DGZfP (in German)

96. Polder R, Andrade C, Elsener B, Vennesland O, Gulikers J, Weidert R, Raupach M (2000) Rilem TC 154-EMC: electrochemical techniques for measuring metallic corrosion-test methods for on site measurement of resistivity of concrete. Mater Struct 33(234):603-611

97. Elsener B, Andrade C, Gulikers J, Polder R, Raupach M (2003) Half-cell potential measurements-potential mapping on reinforced concrete structures. Mater Struct 36(261):461-471

98. Swiss Society of Engineers and Architects (2013) SIA 2006:2013 Planung, Durchführung und Interpretation der Potenzialmessung an Stahlbetonbauten. Schweizerischer Ingenieur- und Architektenverein SIA (in German)

99. Deutsche Gesellschaft für Zerstörungsfreie Prüfung DGZfP (2014) B3: Merkblatt für Elektrochemische Potentialmessungen zur Detektion von Bewehrungsstahlkorrosion. Deutsche Gesellschaft für Zerstörungsfreie Prüfung DGZfP (in German)
100. ASTM International (2015) ASTM C876 standard test method for corrosion potentials of uncoated reinforcing steel in concrete. ASTM International, West Conshohocken

101. Leibbrandt A, Caprari G, Angst U, Siegwart R, Flatt R, Elsener B (2012) Climbing robot for corrosion monitoring of reinforced concrete structures. In: Proceedings 2nd international conference on applied robotics for the power industry (CARPI), ETH Zurich, Switzerland, pp 10-15

102. Stern M, Geary AL (1957) Electrochemical polarization1. A theoretical analysis of the shape of polarization curves. J Electrochem Soc 104(1):56-63

103. Wagner C, Traud WE (1938) Über die Deutung von Korrosionsvorgängen durch Überlagerung von elektrochemischen Teilvorgängen und über die Potentialbildung an Mischelektroden. Zeitschrift für Elektrochemie und angewandte physikalische Chemie 44:391-402

104. Andrade C, Gonzalez JA (1978) Quantitative measurements of corrosion rate of reinforcing steels embedded in concrete using polarization resistance measurements. Mater Corros 29(8):515-519

105. Law DW, Cairns J, Millard SG, Bungey JH (2004) Measurement of loss of steel from reinforcing bars in concrete using linear polarisation resistance measurements. NDT\&E Int 37(5):381-388

106. Andrade C, Alonso C, Gulikers J, Polder R, Cigna R, Vennesland O, Salta M, Raharinaivo A, Elsener B (2004) Test methods for on-site corrosion rate measurement of steel reinforcement in concrete by means of the polarization resistance method. Mater Struct 37(273):623-643

107. Nygaard PV (2008) Non-destructive electrochemical monitoring of reinforcement corrosion. $\mathrm{PhD}$ Thesis, Technical University of Denmark

108. Poursaee A, Hansson CM (2008) Galvanostatic pulse technique with the current confinement guard ring: the laboratory and finite element analysis. Corros Sci 50(10):2739-2746

109. Feliu S, Gonzalez JA, Feliu S, Andrade MC (1990) Confinement of the electrical signal for insitu measurement of polarization resistance in reinforced-concrete. ACI Mater J 87(5):457-460

110. Angst U, Büchler M (2015) On the applicability of the Stern-Geary relationship to determine instantaneous corrosion rates in macro-cell corrosion. Mater Corros 66(10):1017-1028

111. Angst U, Büchler M (2015) Optimizing and validating methods for the determination of the corrosion rate in concrete, research report AGB2012/013, no. 670

112. Martin J, Broughton KJ, Giannopolous A, Hardy MSA, Forde MC (2001) Ultrasonic tomography of grouted duct post-tensioned reinforced concrete bridge beams. Ndt\&E Int 34(2):107-113

113. Iyer SR, Sinha SK, Schokker AJ (2005) Ultrasonic C-scan imaging of post-tensioned concrete bridge structures for detection of corrosion and voids. Comput Aided Civ Inf 20(2):79-94

114. Beard MD, Lowe MJS, Cawley P (2003) Ultrasonic guided waves for inspection of grouted tendons and bolts. J Mater Civ Eng 15(3):212-218 
115. Myrdal R (2007) The electrochemistry and characteristics of embeddable reference electrodes for concrete. CRC Press, Boca Raton

116. Seguí Femenias Y, Angst U, Caruso F, Elsener B (2016) $\mathrm{Ag} / \mathrm{AgCl}$ ion-selective electrodes in neutral and alkaline environments containing interfering ions. Mater Struct 49:2637. https://doi.org/10.1617/s11527-015-0673-8

117. Angst U, Vennesland $\varnothing$ (2009) Detecting critical chloride content in concrete using embedded ion selective electrodes-effect of liquid junction and membrane potentials. Mater Corros 60(8):638-643

118. Angst U, Elsener B, Larsen CK, Vennesland Ø (2010) Potentiometric determination of the chloride ion activity in cement based materials. J Appl Electrochem 40(3):561-573

119. Abbas Y, Zhu X, de Boer HL, Tanvir NB, Olthuis W, van den Berg A (2016) Potentiometric measurement with a Kelvin probe: contactless measurement of chloride ions in aqueous electrolyte. Sensor Actuat B Chem 236: 1126-1132

120. Srinivasan R, Phillips TE, Bargeron CB, Carlson MA, Schemm ER, Saffarian HM (2000) Embedded microsensor for monitoring $\mathrm{pH}$ in concrete structures. Proc Soc Photo Opt Instrum Eng 3988:40-44

121. Nguyen TH, Venugopala T, Chen SY, Sun T, Grattan KTV, Taylor SE, Basheer PAM, Long AE (2014)
Fluorescence based fibre optic $\mathrm{pH}$ sensor for the $\mathrm{pH} 10-13$ range suitable for corrosion monitoring in concrete structures. Sensor Actuat B Chem 191:498-507

122. Seguí Femenias Y, Angst U, Elsener B (2017) PH-monitoring in mortar with thermally-oxidized iridium electrodes. RILEM Tech Lett 2:59-66. https://doi.org/10. 21809/rilemtechlett.2017.37

123. Schiessl P, Raupach M (1992) Monitoring system for the corrosion risk of steel in concrete structures. Concrete Int 14(7):52-55

124. Schiegg Y, Steiner L (2010) Cost effectiveness and application of online monitoring in reinforced concrete structures. Mater Corros 61(6):490-493

125. Schiegg Y, Audergon L, Bohni H, Elsener B (2007) Online monitoring of corrosion in reinforced concrete structures. Eur Fed Corros Publ 38:133-145

126. FHWA (2014) RABIT ${ }^{\mathrm{TM}}$ Bridge Deck Assessment Tool

127. Wells JL, Lovelace B, Kalar T (2017) Use of unmanned aircraft systems for bridge inspections. Transp Res Rec J Transp Res Board 2612:60-66

128. RILEM TC 262-SCI Characteristics of the steel/concrete interface and their effect on initiation of chloride-induced reinforcement corrosion. chair: Ueli Angst, started in 2014 